\title{
CAMPOS DE FORÇA DA ESTÉTICA DE THEODOR ADORNO ${ }^{1}$
}

Luis Satie (UFPB) ${ }^{2}$

luis.satie@alumni-ehess.fr

Resumo: A estética de Adorno se organiza em campos de força, sob os quais orbitam constelações de categorias que traduzem o conteúdo de verdade do mundo administrado na era do capitalismo tardio. Compreender as nuances dessa estética é preparar-se para reinterpretar esse mundo, de sorte a alcançar as coisas esquecidas pelo conceito. Nesse sentido, a estética torna-se uma via para as ciências humanas se reaproximarem da realidade, a partir da recuperação da sensibilidade turbada pela dominação da razão instrumental.

Palavras-chave: Adorno; Estética; Ciências Humanas.

\section{INTRODUÇÃO}

A estética adorniana nos oferece um manancial categórico pouco explorado pelas ciências humanas, ainda presa à compartimentação do conhecimento e, por conseguinte, da própria razão. Para além desse ambiente fragmentado, a estética adorniana anuncia a possibilidade de atualização do pensamento não-estético, tornando-o capaz de atualizar seus próprios problemas. Exploraremos aqui, micrologicamente, esse campo categorial, sempre na perspectiva de sua ubiquidade com relação aos outros saberes.

Quais categorias compõem a constelação negativa da estética adorniana? A partir do estudo da Teoria Estética (TE) de Adorno, agruparemos os elementos que compõem essa

\footnotetext{
${ }^{1}$ Recebido: 16-06-2014/Aprovado: 24-07-2014/Publicado on-line: 08-09-2014.

${ }^{2}$ Luis Satie é Professor Adjunto no Departamento de Filosofia da Universidade Federal da Paraíba, João Pessoa, PB, Brasil.
} 
constelação em cinco campos, sob os quais identificaremos as categorias concernentes a cada um deles: 1) campo lógico-epistemológico, 2) campo político-antropológico, 3) campo ético-pedagógico, 4) campo histórico-natural e 5) campo hermenêutico.

\section{CAMPO LÓGICO-EPISTEMOLÓGICO}

Para Adorno, o campo lógico-epistemológico constitui-se a partir do fato de que toda a experiência da obra de arte está posicionada socialmente. Mesmo a obra mais hermética ultrapassa o seu fechamento monadológico, comunicando-se com a empiria.

Se em Kant o conhecimento não-estético interroga-se sobre a possibilidade de um juízo universal, em Adorno a obra de arte interroga-se acerca da possibilidade do particular. É por intermédio da individuação que a obra transforma o universal no escândalo da arte: "ao tornar-se o que é, a arte não pode ser o que pretende tornar-se" (ADORNO 1982, p. 396). Essa tensão entre o particular e o universal é constitutiva da linguagem da arte na modernidade:

$\mathrm{Na}$ arte, os universais possuem a sua força máxima quando estão mais próximos da linguagem: alguma coisa diz, que, ao ser dito, ultrapassa o seu aqui-e-agora; mas tal transcendência só é alcançada pela arte em virtude da sua tendência para a particularização radical; ao dizer senão o que pode dizer num processo imanente (ADORNO 1982, p. 231-232).

Para Adorno, embora não sejam conceituais, nem formulem juízos, as obras de arte são lógicas e possuem uma racionalidade imanente que as identifica consigo mesmas, dotando-as de objetividade. No entanto, por ser um processo raciocinante sem conceito e juízo, a lógica da arte é pa- 
radoxal: ela atua sobre fenômenos já mediatizados pelo espírito, portanto, já logicizados, renunciando aos fins empíricos.

Não é uma lógica da experiência, mas uma lógica que revela as fraturas da lógica da experiência. Naturalizando a lógica formal, a lógica da arte apresenta-se como uma segunda natureza, desvendando a face mítica do que se acreditava verdadeiro: "[...] na arte, esvanece-se a diferença entre as formas puramente lógicas e as formas que se abrem à objetividade; [nela] hiberna a inseparabilidade arcaica de lógica e causalidade" (ADORNO 1982, p. 158).

Com efeito, o espaço, o tempo e a causalidade são rebatidos para dentro da obra de arte, onde, a um só tempo, se individualizam e refratam-se. Essa refração é forçada pelo caráter de aparência do novo plano, conferindo à arte a condição de experimento da liberdade. Desse modo, a arte imuniza-se contra o pensamento abstrato, que a situa muito além de tais determinações, concedendo-lhe espaço, tempo e causalidade próprios, sem qualquer mediação. Longe de ser essa a esfera ideal, a arte constitui-se de categorias não qualitativamente diferentes das categorias externas. $\mathrm{O}$ que faz a diferença é o meio onde elas se manifestam. Se no âmbito da existência externa essas categorias são dominadoras da natureza, na obra de arte, que lida com elas livremente, serão dominadas. Nas palavras de Adorno, "através da dominação do dominante, a arte revê profundamente a dominação da natureza" (ADORNO 1982, p. 159).

O caráter de inelutabilidade que tais categorias apresentam, na realidade, é desmascarado pela arte quando elas penetram em sua interioridade. Ou seja, a arte revela a aparência do conhecimento empírico ao mimetizar suas formas, submetendo-as ao seu domínio. Essa comunicação da 
arte com a empiria acusa um conflito permanente entre as formas puramente lógicas e as formas objetivas ou, se quisermos, entre logicidade e causalidade. Essa dupla natureza é que garantirá a relação da arte com o seu outro: "Nada há na arte, mesmo na mais sublime, que não provenha do mundo; nada que permaneça intacto. As categorias estéticas devem definir-se tanto pela sua relação ao mundo como pela renúncia a este. A arte é conhecimento em ambos os casos" (ADORNO 1982, p. 160).

Nesses termos, a arte insere-se, criticamente, na Aufklärung, demolindo a ratio dominadora da natureza. Contudo, não se trata aqui de uma negação abstrata: a arte revoga, concretamente, o ato violento da racionalidade, emancipando-a da empiria. A arte inaugura uma nova relação com os objetos, no ato da crítica; é, a um só tempo, utopia e insolência (hybris).

Esse modo sui generis de relacionamento com as coisas foi muito bem percebido por Kant em sua formulação do belo como uma finalidade sem fim. Kant salvaguarda o belo da trivialidade, apesar de desistoricizá-lo, transformando-o numa quimera. Para Adorno, a finalidade imanente das obras de arte constitui-se a partir do que vem de fora, no seu outro, num movimento de liberação dos fins práticos. $\mathrm{O}$ sem finalidade da arte é, pois, a sua aconceptualidade, a sua não-identidade com o conceito, ou melhor, sua nãopredicação ao sujeito. Fiel à sua lógica da diferença, as obras de arte possuem sua própria linguagem, uma linguagem das coisas.

Como se articula essa linguagem do ponto de vista da unidade dialética de forma e conteúdo? Para Adorno, a possibilidade da arte está na forma, a substância de todos os momentos de logicidade. A forma é a coerência dos artefa- 
tos, que faz com que toda obra bem sucedida separe-se do ente:

[...] a forma estética é a organização objetiva de tudo o que, no interior de uma obra de arte, aparece como linguagem coerente. É a síntese não violenta do disperso que ela, no entanto, conserva como aquilo que é, na sua divergência e nas suas contradições, e eis porque ela é efetivamente um desdobramento da verdade (ADORNO 1982, p. 165).

Longe de confundir a forma estética com a forma matemática, Adorno atribui àquela a capacidade de arregimentar os contrários sem resolvê-los, nem reconciliá-los. Como observa Arnold Schoenberg, a forma de uma peça musical indica que ela possui uma organização, que ela é constituída por elementos que se movimentam, como um organismo vivo: "Sem organização, a música seria uma massa amorfa, tão ininteligível quanto um ensaio sem pontuação, ou tão desconexa quanto um diálogo que saltasse despropositadamente de um argumento a outro" (SCHOENBERG 1991, p. 27).

A consonância da obra deve-se a sua forma, mas isso não a protege de ruídos externos. Estes, ao passarem para o interior da obra, sofrem atenuações, são convertidos em ruídos internos, ou melhor, são dominados pela forma, mas não suprimidos. Para José Miguel Wisnik, por exemplo, a história da música é a história da relação entre o som, considerado produção de constância, e o ruído, tomado como perturbação relativa da estabilidade:

O som se produz negando terminantemente certos ruídos e adotando outros, para introduzir instabilidades relativas: tempos e contratempos, tônicas e dominantes, consonâncias e dissonâncias [...] a música contemporânea é aquela que se defronta com a admissão de todos os materiais sonoros possíveis: som/ruído e silêncio, pulso e não-pulso (WISNIK 1989, p. 27-28). 
Esses elementos estranhos permanecem com a sua estranheza, não se harmonizando com a consonância da obra. É essencial à unidade estabelecida pela forma estética que ela se interrompa, que admita a presença do seu outro, embora não se submeta a ele, inserindo-o, todavia, no território da não-violência. Por esse motivo, Adorno define a forma como o elemento antibárbaro da arte. É por meio dela que a arte participa criticamente da civilização. $O$ não formado, o não filtrado pela obra é o pré-crítico. Nesse sentido é que forma e crítica convergem, garantindo a mediatidade, a objetividade da reflexão, em si, da obra.

Do exposto até agora, não se torna difícil compreender que o conteúdo de uma obra de arte encontra-se sedimentado em sua forma, ou seja, a forma é, em si, conteúdo sedimentado: "Tudo o que aparece na obra de arte é virtualmente conteúdo tal como forma, ao passo que esta permanece, no entanto, o meio de definição do que aparece e o conteúdo permanece o que se define a si mesmo" (ADORNO 1982, p. 167). O conteúdo pré-artístico, por intermédio da mediação da forma, converte-se em conteúdo estético, mas não perde sua qualidade de conteúdo, subsistindo a diferença. Isto é, se, de um lado, a forma, necessariamente, submete-se à mediação do conteúdo pré-artístico, do qual ela se origina; de outro, na obra não há mais lugar para o conteúdo pré-artístico ou pré-crítico; tudo nela é conteúdo estético, é forma ou, se quisermos, conteúdo crítico que aparece enigmaticamente. Decifrar esse enigma é decifrar o conteúdo de verdade da obra; para Adorno, é esse o papel da reflexão filosófica.

Se, na Teoria estética, Adorno não confunde conteúdo e forma, o mesmo acontece com a relação sujeito-objeto, como aduz Martin Jay no texto Sujeito-objeto (1988). Segundo 
Jay, o termo sujeito, utilizado por Adorno, significa tanto o indivíduo particular quanto a consciência em geral, pois não podemos fazer referência ao nosso ego individual prescindindo de um conceito (JAY 1988, p. 56). Nesse passo, sujeito pode ser tanto o que domina, como o que é dominado. Paradoxalmente, por conseguinte, o sujeito também é objeto, o que, desde Descartes, não se admite na epistemologia ocidental, que insiste na separação radical entre esses dois termos. Para Adorno, tal separação é verdadeira - na medida em que atesta a atual dicotomia da condição humana - e falsa, ao hipostasiar-se numa invariante. Melhor: a separação é, ao mesmo tempo, real e ilusória - é real quando descreve e ilusória quando prescreve.

Para Jay, Adorno admite a cisão como uma verdade descritiva e não como verdade normativa, desconsiderando a premissa hegeliana de que há necessariamente um deverser, em estado latente, na descrição dialética do ser. Vale dizer que o todo não é o que deve ser; é o falso, razão pela qual a verdade normativa só pode ser encontrada nas ruínas de uma realidade que escape ao poder totalitário dessa totalidade vigente (JAY 1988, p. 58).

Tanto o positivismo quanto o idealismo expressam filosoficamente o momento da dominação do objeto pelo sujeito. Travestido de uma aparente passividade e neutralidade, o sujeito positivista submete os objetos ao seu projeto de mundo. De outra parte, acreditando que o mundo é o produto de uma consciência que se reconhece em suas criações objetivas, o sujeito idealista traga os objetos, coagindo-os a afirmá-lo. Em ambos os casos, o que se percebe é a rejeição à diversidade do mundo natural.

Segundo Jay, ao rejeitar os dois modelos, Adorno propõe a preponderância do objeto (JAY 1988, p. 59). Todavia, 
não é por meio de um retorno ao estado natural que a cisão sujeito-objeto deve ser superada, mas por meio da comunicação entre um e outro, conditio sine qua non da realização da paz na diferença, em que cada elemento distinto participaria do outro (JAY 1988, p. 61).

Nesses termos, o propósito de um pensamento crítico não seria o de entronar o objeto em detrimento do sujeito, mas abolir a hierarquia entre eles, emancipando a diferença. Adorno entende por preponderância do objeto o processo de sua desidentificação com o sujeito. Sem dúvida, é na experiência estética que Adorno observa um ensaio dessa peculiar reconciliação epistemológica.

Com efeito, na Teoria estética, Adorno emprega a expressão sujeito-objeto de modo dialético; ou seja, tendo em vista que o sujeito é sempre já objetivo, a subjetividade coletiva e individual sofre a contra-atração do objeto: "em toda a obra de arte ata-se o nó do universal e particular" (ADORNO 1982, p. 188).

Na Crítica da Faculdade de Julgar, Kant já pressentira esse fenômeno como um problema: o belo não se define pelo conceito, pois é o que agrada universalmente, sem conceito. Segundo Adorno, Kant sofre uma contra-atração irresistível do objeto em sua última Crítica, mas permanece amarrado à lógica discursiva (ADORNO 1982, p. 187), na medida em que atribui, erroneamente, um caráter subjetivo ao sentimento estético, contaminando-o com as emoções psicológicas imediatas, que excitam o prazer ou o desprazer.

Por conseguinte, Kant desconhece a capacidade que a experiência estética possui de modificar a experiência real. Para Adorno, no entanto, o sentimento estético resulta da objetividade; é mais espanto do que prazer, o espanto de um ser totalmente dominado pelo ininteligível, pelo não- 
idêntico, como podemos perceber nessa ilustrativa passagem de Rainer Maria Rilke, acerca da obra de Auguste Rodin:

Quando vem a primeira inspiração de um tema, quando uma lenda da Antiguidade, um poema, uma cena histórica desencadeiam a criação, esse elemento, no começo do trabalho de Rodin, se traduz em algo cada vez mais não-nomeado e objetivo: na transferência para a linguagem das mãos, as exigências do tema assumem um sentido totalmente novo ligado à realização da escultura (RILKE 1995, p. 59).

A crítica de Adorno se estende à Hegel. Apesar de ter ressaltado o momento da objetividade, em oposição a Kant, Hegel igualmente subsume a objetividade da coisa à objetividade do espírito absoluto, permanecendo na afirmação da identidade.

As estéticas subjetiva e objetiva, enquanto polos contrários, expõemse igualmente à crítica de uma estética dialética: aquela, porque é abstrata e transcendental ou contingente, segundo o gosto do indivíduo - esta, porque desconhece a mediatização objetiva da arte pelo sujeito. Na obra, não é o sujeito nem o contemplador, nem o criador, nem o espírito absoluto, mas antes o que está ligado à coisa (Sache) (ADORNO 1982, p. 189).

\section{CAMPO POLÍTICO-ANTROPOLÓGICO}

A coisa, portanto, é sujeito sedimentado, expresso objetivamente. E é com base nessa constatação que penetraremos nas linhas do campo de força político-antropológico, no qual Adorno interroga o papel do indivíduo como sujeito da experiência.

Segundo Buck-Morss, Adorno procura redimir o conceito de indivíduo, recuperando-o do naufrágio do individualismo burguês. Em lugar de uma concepção marxiana da consciência de classe como experiência política, Adorno 
desenvolve uma concepção da consciência individual como sujeito da experiência cognitiva. Ele regressa a Kant, fazendo eco ao apelo de Ernst Bloch de manter a atualidade de Kant através de Hegel (BUCK-MORSS 1981, p. 178).

Se, para Kant, o sujeito não pode pretender experimentar o objeto em si, senão por meio de formas e categorias subjetivas, tratando o objeto como idêntico ao sujeito, para Adorno a relação inverte-se: o objeto recupera sua órbita em torno do sujeito, sublevando a revolução copernicana de Kant e remetendo o sujeito à experiência da nãoidentidade.

Ao rechaçar a ideia de um sujeito transcendental, o sujeito da experiência filosófica, Adorno vislumbra um ser humano empírico, material e transitório, um corpo humano que sente ou, se quisermos, um pedaço de natureza (stück Natur). Ademais, para atingir a felicidade sensual (sinliche Glück), objetivo da sociedade, o conhecimento deve não só reconhecer a realidade do sofrimento humano, como afirma Horkheimer, mas assumir seu caráter somático. Nesse ponto, Buck-Morss identifica em Adorno a influência de Walter Benjamin, para quem o pensamento é inseparável do mundo sensível.

Contudo, Adorno não se questiona acerca da origem de classe ou da posição particular do sujeito dentro das relações sociais de produção. Para ele, tanto a burguesia quanto o proletariado podem ser igualmente portadores ideológicos da falsa totalidade. Adorno aposta, todavia, na capacidade do indivíduo em resistir à identificação com o status quo, por meio da experiência cognitiva. Por isso, segundo Buck-Morss, o conceito de experiência em Adorno não inclui, nem sequer supõe, uma teoria da intersubjetividade, visto que a verdade objetiva não depende do consen- 
so subjetivo. Nesse sentido, Adorno faz duo com Benjamin, ao afirmar que a comunicação, como instrumento da indústria cultural, em particular, e da universalidade, em geral, isto é, como estratégia de circulação de mercadorias, não é condição nem critério da verdade, podendo, ao contrário, falseá-la:

La imediata comunicabilidade a cualquiera no es el criterio de lo verdadero. Ahora que todo paso hacia la comunicación vende y falsea la verdad, es preciso resistir a la coacción casi universal que hace confundir lo conocido con su comunicación e incluso poner a ésta por encima. Todo lo que es lenguage padece entre tanto bajo esta paradoja. La verdad es objetiva y no plausible (ADORNO 1975, p. 49).

No entanto, ao contrário do que possa parecer, esse inconformismo intelectual postulado por Adorno não se confunde com elitismo, nem é indiferente aos conflitos de classe; apenas parte de uma compreensão lúcida do perigo totalitário que ronda o reino da experiência política após o nazifascismo e o stalinismo. Noutros termos, não se trata de elitismo, mas de rigor teórico e crítico, aliado ao desesperado cuidado de sauvetage da razão.

$\mathrm{Na}$ Teoria estética, com efeito, a arte representa um modelo de práxis objetiva, na medida em que põe, implacavelmente, em cena a crítica radical ao mundo real. Para Adorno, a arte contribui para o processo de desconstrução do ego, a ponto de fazê-lo perceber seus limites e sua finitude. No entanto, esse abalo não conduz ao enfraquecimento do eu, promovido preponderantemente pela indústria cultural. Enquanto esta última o aprisiona pela mitificação do prazer, a arte o insere na mais extrema tensão: a tensão entre o que é e o que pode ser. E é aí que reside o engagement imanente da arte: "A dialéctica do elemento social e do em- 
si das obras de arte é uma dialéctica da sua própria nature$z a$, na medida em que não toleram nenhum elemento interior que não se exteriorize, e nenhum elemento exterior que não seja portador da sua interioridade - do conteúdo de verdade" (ADORNO 1982, p. 277).

Adorno vê, desse modo, o artista como um trabalhador, não como um interlocutor da mensagem. Estar, portanto, diante do material é estar diante de um problema a ser resolvido e cuja solução encontra-se potencialmente no próprio material: "Se ao utensílio se chamou um braço prolongado, poder-se-ia chamar ao artista um utensílio prolongado, utensílio de passagem da potencialidade à atualidade" (ADORNO 1982, p. 190).

Nesse sentido, o verdadeiro sujeito da obra não é quem a produz ou quem a recebe, mas quem fala por intermédio dela. $\mathrm{O}$ eu latente é imanente à coisa, que se expressa na forma da obra. O eu do artista está para o eu da coisa, assim como o particular está para o universal. A força que faz com que o eu privado se exteriorize no objeto é a essência coletiva, que sobrepuja esse eu. Como nota Marc Jimenez:

A individuação, no sentido em que o sujeito é antes de tudo Gesamtsubjekt, representante da tendência social geral, não entra em contradição com a objetivação. O indivíduo, por sua imersão em si próprio, registra o sofrimento do mundo alienado, que só se traduz pela forma, porque é graças a ela que a arte transcende o sujeito implicado na sociedade (JIMENEZ 1977, p. 170).

A esse encontro dialético do particular com o universal é que Adorno atribui o caráter linguístico da obra. Em verdade, o trabalho da obra de arte é social, manifestado por intermédio do indivíduo, mesmo que este não tenha consciência disso. Aliás, quanto menos consciente for, maiores as chances de o Outro se expressar. Ou seja, o indivíduo é o 
mínimo que a obra precisa para cristalizar-se, pois o que fala por meio da obra é um nós, não um eu, não um nós unívoco, de posição social ou de classe determinada, mas um nós cindido. Assim, ao mesmo tempo que testemunha o irreconciliável, os antagonismos sociais, a arte tende à reconciliação, apontando para um sujeito e uma sociedade não existentes: "as obras de arte devem surgir como se o impossível fosse possível” (ADORNO 1982, p. 193).

Em sua concepção minimalista do eu privado, Adorno critica o conceito idealista de gênio, que faz coincidir o indivíduo com um sujeito absoluto, tornando também absoluto o particular e desviando-o da sociedade. Em verdade, Adorno tenta redimir o conceito de gênio, iluminando-o a partir da coisa. Genial é o instante em que a participação da obra de arte na linguagem abandona a convenção e ressalta o contingente: "O genial é um nó dialético: o não rotineiro, o não repetido, o que é livre, o que simultaneamente traz consigo o sentimento do necessário, a pirueta paradoxal da arte e um dos seus critérios mais fidedignos" (ADORNO 1982, p. 195). Contudo, a tensão existente entre o livremente inventado e o necessário faz com que o genial permaneça paradoxal e precário: "Sem a possibilidade presente da catástrofe, nada é genial nas obras de arte" (ADORNO 1982, p. 195-196).

Adorno também submete à crítica o conceito de fantasia, definida tradicionalmente como a capacidade de produzir um determinado ente artístico, a partir do nada. Ora, se as obras se opõem ao existente é porque a imaginação o rejeita a partir dele. Não há creatio ex nihilo na arte: "Somente mediante o ente é que a arte se transcende em não-ente; de outro modo, ela torna-se a projecção impotente do que de qualquer modo é" (ADORNO 1982, p. 197). Ao conside- 
rar o artista como um trabalhador, Adorno não separa a fantasia do trabalho de reflexão. Nesses termos, a separação teórico-cognoscitiva entre sensibilidade e entendimento é refutada pela arte. Se uma obra envolve um conjunto de problemas, fantasia é a faculdade de descobrir soluções. Com isso, o conceito de fantasia adquire, em Adorno, o estatuto de uma categoria diferencial da liberdade em face da determinação.

\section{CAMPO ÉTICO-PEDAGÓGICO}

É possível localizarmos na Teoria estética as linhas de um campo de força ético-pedagógico? Julgamos que sim, desde que consideremos que a obra de arte, para Adorno, possibilita o aprendizado da transgressão do ente, ao ensaiar a configuração de um não-ente.

Ao estabelecer uma distância entre o espectador e o objeto, a experiência estética exige a autonegação do espectador, o que a caracteriza como um movimento contrário ao sujeito: "[...] a experiência estética [...] desfaz o sortilégio da estúpida autoconservação, modelo de um estado de consciência em que o eu deixaria de ter a sua felicidade nos seus interesses, por fim, na sua reprodução" (ADORNO 1982, p. 381).

Assim, a arte é uma linguagem do sofrimento, um testemunho de nossas misérias, ao mesmo tempo que inventa a novidade, a utopia. Aliás, como antítese social da sociedade, a arte é uma forma de práxis, um modo de conduta. Para Adorno a práxis não está no efeito de prazer que as obras possam gerar no indivíduo, mas no seu conteúdo de verdade.

Se a arte participa da moralidade, não é por meio da 
promulgação de máximas morais, nem pela obtenção de efeitos morais nos seus receptores, mas por negar a brutalidade perante as coisas, negando, por conseguinte, a brutalidade para com os homens/mulheres. Podemos, portanto, falar de uma racionalidade estética, uma racionalidade crítica, porque, ao derrubar as fronteiras entre a sensibilidade e o entendimento, inaugura uma nova relação com os objetos, instituindo a diferença na identidade.

Todavia, a participação da racionalidade da arte na moralidade só se dá por meio da recusa, sendo a forma o selo de um trabalho social que seleciona, amputa e renuncia os seus materiais: "A arte cai no pecado do vivo a fim de o trazer à linguagem, e o mutila” (ADORNO 1982, p. 166). Desse modo, prolonga-se na arte a dominação que ela própria critica. Imersas num mundo contraditório, as obras de arte estão fadadas ao declínio. Inserem-se na tragédia social, não só porque são heteronomamente dependentes, mas porque em sua própria constituição autônoma condensam os antagonismos: "Ao seu próprio conceito está mesclado o fermento que a suprime" (ADORNO 1982, p. 15).

Seu caráter pedagógico emerge em razão do métier artístico ser uma revolução permanente do estado das forças produtivas estéticas; é disso que depende a possibilidade da arte: "Não se pode decidir a partir de cima, segundo o critério das relações de produção, se a arte é hoje ainda possível. A decisão depende do estado das forças produtivas" (ADORNO 1982, p. 282).

Para não estagnar, ou sucumbir à técnica, os artistas não podem menosprezar o estado atual dos materiais, pois é neles que a história sedimenta-se; é deles que se deve extrair o conteúdo de verdade da obra. Adorno concorda com Marx quando este assevera que cada época resolve os pro- 
blemas que lhe são colocados. $\mathrm{Na}$ arte, a consciência mais progressista é aquela que se assegura da atualidade dos problemas colocados nos materiais. Assim, o métier é concreto, pois é o exercício de ultrapassagem permanente dos procedimentos técnicos. A arte domina a técnica ao penetrar no desconhecido e rejeitar o status quo, ensaiando soluções que tomem por base as tensões do mundo administrado.

Adorno define o comportamento estético como a capacidade de perceber nas coisas mais do que elas são, o corretivo perfeito da consciência reificada. Também o define, em última análise, como a capacidade de estremecer-se diante do não-idêntico ou da subjetividade que ainda não é. Esse estremecimento ocorre quando o ser é tocado pelo outro, momento de objetivação da subjetividade, ponto de encontro entre eros e o conhecimento.

Enfim, a arte é fenômeno ético-pedagógico na medida em que apresenta um conteúdo de verdade. A obra de arte constitui-se como um ser à segunda potência no processo de separação crítica da empiria, quando reinstitui em território próprio a relação do todo com as partes. Desse ponto de vista, a obra pode ser compreendida como um ente empírico emancipado de suas misérias. Consideradas como linguagem do não-idêntico, as obras de arte são vivas: "a arte é o mundo uma vez mais, a ele tão semelhante como diferente" (ADORNO 1982, p. 370).

Se a arte promete o que não é, no entanto, no ato de sua aparição, anuncia objetivamente a possibilidade da promessa. Parafraseando o que Marx escreve a respeito da religião em sua crítica à filosofia do direito de Hegel, podemos dizer que a miséria da arte é, para Adorno, a um só tempo, a expressão da miséria real e protesto contra ela, o suspiro da criatura aflita, o estado de ânimo de um mundo 
sem coração, por ser o espírito da situação sem espírito. Se é o ópio do povo, o é por revelar a tensão entre o real e o imaginário.

Essa tensão entre utopia e possibilidade imprime-se nas obras de arte, inserindo-as na catástrofe, da qual elas próprias dão o testemunho, mediante sua efemeridade. Por isso, Adorno utiliza-se da alegoria do fogo de artifício para falar da verdade da arte. $O$ fogo de artifício é uma aparição empírica liberta do peso da empiria, bem como da duração, do tempo administrado; é um sinal produzido de uma só vez, configurando uma escrita ao mesmo tempo fulgurante e fugidia, que não se permite à significação, de sorte que a verdade da arte, como aparição, não é passível de troca, pois não é um equivalente, uma generalidade vazia que a tudo nivela, nem algo inerte que possa ser substituído por outra coisa.

Sua verdade é a diferença, é o infungível. Assim como o fogo de artifício não permanece, também as obras de arte não garantem sua promessa, confessando-se incapazes de convocar o não-ente que anunciam para a existência. Elas interiorizam em si os antagonismos sociais, bem como a cisão histórica de sujeito e objeto, comburentes necessários para a explosão da aparência, momento em que se liberta a essência do que aparece, quando se exterioriza o seu grito interior, rebentando o invólucro da empiria. Por meio do seu próprio sacrifício, as obras de arte antecipam o apocalipse, crendo na possibilidade do impossível:

A pesar de que la sociedad exige moralidad, ésta sólo puede existir realmente en una sociedad liberada; en la sociedad socializada no hay individuo que pueda ser moral. La única moral aún posible es terminar de una vez com la mala infinitud, el canje atroz de represalias. Hasta entonces el individuo no puede disfrutar de outra moralidad que la absolutamente despreciada por la ética kantiana, cuando 
a los animales les concede inclinación, pero no respeto: la de intentar vivir de modo que se pueda creer haber sido un buen animal (ADORNO 1975, p. 296).

\section{CAMPO HISTÓRICO-NATURAL}

Ingressemos, agora, nas linhas do campo histórico-natural, valendo-nos mais uma vez de Buck-Morss, mais exatamente do capítulo em que ela comenta a dialética sem identidade, com base na ideia de história natural de Adorno. Segundo a autora, foram os estudos musicais de Adorno que o conduziram a refletir acerca da dimensão histórica de um modo muito peculiar. Para Adorno a música, por ser uma arte temporal, é marcada pela irreversibilidade de seu movimento, que a compele a desenvolver-se a si mesma (BUCKMORSS 1981, p. 102). Ou seja, a obra contém uma historicidade que lhe é imanente, reflexo das condições históricas objetivas.

Em vez de atemporal, abstrata e imortal, a forma musical insere-se num tempo próprio, é concreta e transitória, não obedecendo a leis eternas de composição. Schoenberg tinha isso bastante claro quando deflagrou o processo de ruptura com a tonalidade, desmitificando as pretensas "leis naturais" da música; segundo ele, a arte desenvolve-se por meio das obras e não de acordo com qualquer tipo de princípio transcendente ou padrão histórico. As leis formais do passado não devem servir de parâmetro para a criação do presente (BUCK-MORSS 1981, p. 105).

Ao contrário de Lukács que vislumbra na revolução proletária a possibilidade de restabelecimento da totalidade perdida, de reconciliação entre sujeito e objeto, Adorno insiste na negação da identidade entre razão e realidade: a história é descontínua, não é uma totalidade estruturada. 
Assim, Adorno rejeita a concepção hegeliana da história como identidade entre o racional e o real, bem como todas as interpretações da história como progresso.

Segundo Buck-Morss, Nietzsche já alertara sobre o perigo dessas interpretações, por buscarem a racionalização do sofrimento (BUCK-MORSS 1981, p. 110). Adorno expressa a mesma crítica, ao afirmar em sua conferência inaugural, Die Aktualität der Philosophie, apresentada em 1931 na faculdade de filosofia de Frankfurt, que a razão não pode surgir de uma realidade estruturada pelo irracionalismo (BUCK-MORSS 1981, p. 109).

Ora, se a história não tem razão, não há que se falar de uma filosofia da história. Segundo Buck-Morss, história e natureza são, para Adorno, opostos dialéticos, utilizados como conceitos cognitivos, isto é, como ideias reguladoras que se criticam mutuamente: a natureza revela a nãoidentidade entre o conceito de história e a realidade histórica, ao passo que a história desmitifica o conceito de natureza.

Ou seja, a história real passada não se identifica com o conceito de história como progresso racional, em razão da violência a que foi submetida a natureza material; os fenômenos "naturais" do presente, por sua vez, não se identificam com o conceito de natureza como realidade essencial, por terem sido produzidos historicamente. Considerando essa interrelação dialética, nem uma, nem outra, podem adquirir o estatuto de um primeiro princípio ontológico (BUCK-MORSS 1981, p. 113).

Ao desmitificar tais ideias, Adorno libera o presente do fatalismo ou da necessidade, recuperando a possibilidade da catástrofe, do "progresso" como desintegração progressiva, sendo a verdade da obra de arte estreitamente ligada a 
sua própria decadência (BUCK-MORSS 1981, p. 116).

Ao estabelecer o presente como ponto de referência, Adorno busca evitar, ao mesmo tempo, a metafísica e o relativismo histórico. Não é o presente que obtém seu significado da história; é a história que é significada pelo presente. Como aduz Buck-Morss:

Si los historicistas relativizaban el presente al situar los fenómenos cotidianos dentro de un desarrollo histórico general, el procedimento de Adorno era inverso: el presente relativizaba el passado. La historia cobrava sentido sólo en tanto se manifestaba como "historia interior" dentro de los fenómenos presentes (BUCK-MORSS 1981, p. 117).

Desse modo, se a história participa da constelação da verdade, é sem nenhum propósito de salvação permanente, graças à vulnerabilidade do presente e à precariedade da verdade. Essa inversão da relação entre presente e passado é o que Benjamin denomina de revolução copernicana do enfoque histórico (BENJAMIN 1985a). Para enfocar o presente, entretanto, impõe-se não apenas analisar dialeticamente a relação entre os conceitos de história e natureza, mas também verificar a dialeticidade em si, imanente em cada conceito.

Segundo Buck-Morss, Adorno, em sua conferência Die Idee der Naturgeschichte, atribui à história um significado positivo e um negativo. $O$ positivo é a práxis social dialética, um comportamento social que aponta para o qualitativamente novo; quanto ao negativo, está presente na não historicidade de uma práxis que apenas reproduz as condições e relações de classe.

Do mesmo modo, a natureza possui um polo positivo, materialista, quando se refere a entes concretos, individuais, mortais e transitórios, no momento em que o natural 
dá corpo à história. Seu polo negativo apresenta-se naquilo que ainda não foi incorporado à história, no que ainda não foi penetrado pela razão. Aqui, a natureza é o que se repete, é o mítico.

Eleger um ou outro desses conceitos como primeiro princípio ontológico implicaria na perda do seu duplo caráter, inibindo a crítica e, por conseguinte, justificando a ordem social dada. $O$ procedimento de Adorno é o de, ao mesmo tempo, desconstruir a história como natureza e reconstruir a natureza como ente histórico. Mas como proceder para "desencantar" os conceitos de natureza e história?

Para isso, Adorno cria mais dois pares de conceitos, a saber, o de primeira natureza, para se referir ao mundo sensível, definido como a natureza concreta e particular, e o de segunda natureza, para se referir ao mundo das convenções burguesas, o mundo alienado. Portanto, para revelar a dimensão histórica do que aparece como "natural", como uma realidade "dada", é preciso que se dirija o enfoque ao momento da produção social daquele fenômeno, de sorte a desvelar seu caráter de segunda natureza, histórico, já que produzido pela má infinitude ou falsa totalidade.

De outra parte, se quisermos evitar o encantamento da história, é necessário que ela seja interpretada do ponto de vista da primeira natureza, do sofrimento do mundo sensível, do contingente. Por isso, segundo Benjamin (1985a), a história deve ser tratada como alegoria, que é a exposição simbólica da história como tragédia, como sofrimento, ou, segundo Adorno, como o modo mais adequado de retratar a verdade numa época de decadência histórica. Tanto o conceito de segunda natureza como o conceito alegórico de história têm o mérito de trazer à luz a transitoriedade da realidade material. E é justamente esse momento de transito- 
riedade que faz convergir, mais intensamente, natureza e história.

Como a obra de arte comporta-se diante desses conceitos cognitivos de história e natureza, já que ela realiza, concretamente, por meio de sua efemeridade, o encontro dialético aqui referido? Um importante aspecto a ser destacado é o problema da origem. Para Adorno, a essência da arte não é dedutível de sua origem; não há um fundamento primeiro sobre o qual a história da arte se sustente. A arte não é corolário de nenhum axioma original, não devendo ser definida dogmaticamente: "a arte tem o seu conceito na constelação de momentos que se transformam historicamente" (ADORNO 1982, p. 12).

Por essa razão, não há que se falar das primeiras obras de arte como as mais elevadas ou as mais puras, crença atribuída por Adorno a um romantismo tardio, que não se desprende de uma certa nostalgia da origem. A arte deve ser captada em seu movimento, em seu devir. Inspirado em Nietzsche, Adorno afirma que a verdade só existe como o que esteve em devir. Ou seja, as obras de arte só adquirem identidade no processo de negação permanente de sua origem. A arte determina-se, pois, na relação com o que ela não é: "O carácter artístico específico que nela existe deve deduzir-se, quanto ao conteúdo, do seu Outro; apenas isto bastaria para qualquer exigência de uma estética materialista dialética" (ADORNO 1982, p. 12).

Mas como fica a relação da arte com a tradição, já que esta não deve ser parâmetro para aquela? Ora, para Adorno a tradição não deve ser negada de maneira abstrata; ela deve ser criticada com base na situação presente. Coerente com o texto da sua conferência Die Idee der Naturgeschichte, Adorno mantém na Teoria Estética a ideia de que o presente 
constitui o passado. $\mathrm{O}$ tempo não é critério absoluto para a crítica, seja porque não devemos aceitar algo só pelo fato de ter validado alguma coisa no passado, seja porque não devemos eliminar nada só por não participar da contemporaneidade.

Por conseguinte, a novidade não deve aprisionar-se ao passado, tombando diante da máxima conformista a enunciar que "tudo já foi feito", nem negá-lo absolutamente, fiando-se numa invenção a partir do nada. Ao contrário, o novo possui sua especificidade, bem como o seu conteúdo de verdade próprio, ao articular objetivamente o indivíduo e a sociedade diante da problemática mais atual.

Ao deslocar toda a dor cósmica (Weltschmerz) para o inimigo, a saber, o próprio mundo, o novo aparenta-se com a morte, "a nouveauté, do ponto de vista estético, é um produto do devir" (ADORNO 1982, p. 33), um devir concreto que brota da própria coisa como história sedimentada; um devir da diferença. Daí que a arte deve e pretende ser utopia, mas apenas à medida que negue o existente a partir dele.

Adorno, em passagem memorável, sugere o exemplo de uma criança que busca no piano um acorde nunca ouvido. No entanto, tal acorde já se encontra no teclado, sendo limitadas as possibilidades de combinação, que serão buscadas por meio da experiência: "o novo é a nostalgia do novo" (ADORNO 1982, p. 45). O devir e a indefinibilidade das obras apontam, nesse passo, para o caráter descontínuo da história da arte.

Todavia, não há que se condenar a arte por ela não apresentar condições de realizar a utopia; afinal, não é outro o dilema da teoria, tão impotente quanto aquela: "Pela recusa intransigente da aparência de reconciliação, a arte 
mantém a utopia no seio do irreconciliado, consciência autêntica de uma época, em que a possibilidade real da utopia [...] se conjuga, num ponto extremo, com a possibilidade da catástrofe total" (ADORNO 1982, p. 46).

A propósito, em que medida podemos falar de progresso na arte, já que seu conteúdo de verdade, do qual depende sua qualidade, é histórico? Mais uma vez, o tempo, como categoria externa às obras, não é o critério sob o qual devam se subsumir seu conteúdo de verdade e sua qualidade. Isso porque a história é imanente às obras e não um destino exterior que as sobrepuje. Segundo Adorno, a historicidade do conteúdo de verdade é concedida pela objetivação, nas obras, da consciência verídica.

Diante do crescimento do potencial de liberdade no curso do mundo, a consciência verídica nada mais é do que "a consciência mais progressista das contradições, no horizonte da sua possível reconciliação" (ADORNO 1982, p. 217). Ou seja, é a consciência do problema, que se aloja no estado atual das forças produtivas estéticas, no material, onde a história se condensa. Por esse motivo, podemos nos referir às obras como historiografia inconsciente, como atualização permanente dos antagonismos sociais.

Nesse sentido, Adorno considera haver tanto e tão pouco progresso na arte como na sociedade. Perceber essa relação entre arte e verdade foi o mérito da estética de Hegel, muito embora ele tenha circunscrito essa verdade no cânone da antiguidade, refreando a possibilidade do progresso artístico. Entretanto, Hegel não percebera que a incapacidade das obras, no período romântico, de refletir o conteúdo de verdade do espírito absoluto não era mais que o reflexo do fracasso do próprio espírito, perante o escândalo da particularidade. 
Essa relação dialética entre natureza e história também se apresenta nas ideias de belo natural e belo artístico. Adorno ensina que o belo natural, objeto da Crítica da Faculdade de Julgar de Kant, foi recalcado pelo conceito hegeliano de belo artístico. Refletir sobre ele é, portanto, tocar numa ferida, o que reveste esta reflexão de um caráter inalienável na teoria da arte, muito embora a temática possa parecer monótona e arcaica.

Não obstante, se o conceito de belo natural desapareceu da estética, foi em razão da dominação crescente do conceito kantiano de liberdade e dignidade humana, segundo o qual "nada no mundo se deve respeitar, a não ser o que o sujeito autônomo a si mesmo deve" (ADORNO 1982, p. 78). O que aqui aparece como verdade de uma liberdade para si é, ao mesmo tempo, uma inverdade, a saber, a servidão para com o outro.

Para Adorno, se o ato de imputar o belo à natureza atende à necessidade do idealismo de perseguir o nãoidêntico - tragando-o em nome do autoengrandecimento conceitual do homem, em detrimento de sua animalidade sensível -, carrega consigo, na mesma medida, a crítica ao fabricado, ao útil, ao descartável.

De certa forma, em Kant, o sentimento do belo natural canaliza o sofrimento do sujeito diante de um mundo pronto e instituído, fazendo eco à crítica de Rousseau. $O$ belo natural aparece como crítica à civilização, ao modo como ela se relaciona com os objetos. A contemplação desinteressada das imagens da natureza coloca o sujeito diante do desconhecido, do indefinível e do inútil. Nesse contato, o sujeito não se afirma, não se consola, não se autoconserva: ele se aterroriza perante o não-dominado.

Em vista disso, Adorno, dando razão à Kant, considera 
que o belo artístico, embora distinto da natureza, almeja manter o que ela promete ao traduzi-la in effigie; assim, as características do belo natural migram para a arte, por meio de um movimento de passagem do imediato para o mediato ou, se quisermos, por meio da liquidação do mito, ou seja, da natureza como destino.

Isso posto, Adorno critica o belo natural enquanto conceito fixo, redefinindo-o como histórico. Assim, quando Verlaine afirma, para seguir um exemplo do próprio Adorno, que o mar é mais belo que as catedrais, está afirmando ou negando o convencional, conforme o mar esteja ou não integrado ao circuito das mercadorias.

Transparece, aqui, a não-identidade, o primado do objeto na experiência subjetiva. Logo, podemos asseverar que, para Adorno, a arte, em vez de imitação da natureza, é imitação do belo natural, na medida em que este é história suspensa, um devir interrompido, indeterminado, indefinível e negativo: um belo natural em si, que se recusa à comunicação: "A dignidade da natureza é a de um ainda-nãoente, que recusa através da sua expressão a humanização intencional [...] Pois, a comunicação é a adaptação do espírito ao útil, mediante a qual ele se integra nas mercadorias, e o que hoje se chama sentido participa desta monstruosidade" (ADORNO 1982, p. 91).

Nesse passo, o silêncio é a linguagem da natureza e a obra de arte torna-se a linguagem desse silêncio, a lembrança da diferença sob o sortilégio da identidade universal. Contudo, é somente por meio da mediação do que já é mediatizado na arte que conseguiremos escutar esse silêncio imanente. Operar essa segunda reflexão é, para Adorno, o papel de uma filosofia que anseie manter suas promessas. 


\section{CAMPO HERMENÊUTICO}

Mas como nos abandonaremos ao objeto, em busca do seu enigmático conteúdo de verdade, por meio do conceito? Segundo Buck-Morss, Adorno, influenciado por Benjamin, responde ao dilema da filosofia burguesa de enaltecer o universal, o necessário, o conceitual e rejeitar o particular, o contingente, o carente de conceito, com uma guinada rumo ao objeto, ao particular concreto. Isso, porque, para ele, a autonomia da razão, tese de todo sistema idealista, que se supunha capaz de desenvolver o conceito de realidade com base em si mesma, não tem mais sua razão de ser. Realidade e razão não se harmonizam (BUCK-MORSS 1981, p. 155).

Todavia, Adorno não abandona a totalidade para situar-se, confortavelmente, no particular. Aliás, essa atitude, assumida pela Fenomenologia de Husserl e pelo Existencialismo, que não ultrapassam o objeto dado imediatamente, amarrando-se ao fetiche, à forma reificada, em detrimento da natureza social da coisa, foi criticada por Adorno. Segundo ele, o particular deve ser relacionado dialeticamente com a totalidade, pois o objeto é mais do que o objeto mesmo. Por conseguinte, o geral encontra-se dentro das características do particular e a verdade habita o aparentemente mais insignificante, atípico ou estranho (BUCKMORSS 1981, p. 161).

Essa propensão à análise microcósmica é uma herança de Benjamin, a quem Ernst Bloch atribuía uma extraordinária percepção para o individual, o inusual e o nãoesquemático (BUCK-MORSS 1981, p. 162). Ao utilizar-se dessa mirada microscóspica como ferramenta para o conhecimento filosófico, Adorno aspira à dissolução da aparência reificada, intentando liberar a significação do objeto. 
Esse perder-se na contingência, todavia, também apresenta uma dimensão utópica. Com efeito, nessa abordagem, o particular não constitui um caso do geral; como as mônadas de Leibniz, cada particular é único, contendo, ao mesmo tempo, uma imagem do todo ou, como quer Benjamin, uma imagem do mundo. Ora, à medida que o particular é transitório e resiste à categorização, desafia a estrutura social burguesa, que expressa a seu modo.

Segundo Buck-Morss, Adorno toma emprestado de Bloch a ideia de leitura da não-identidade dos particulares como promessa da utopia. A não-identidade é o lugar da verdade, mas de uma verdade inintencional, cuja interpretação deve se dar pela justaposição analítica de seus elementos, mantendo, cada um deles, com a totalidade sua relativa independência, de modo a poder iluminar o real sufocado pelo pensamento identificador. Novamente Adorno faz eco às palavras de Benjamin, para quem o objeto de conhecimento, como algo determinado dentro da intenção conceitual, não é verdadeiro (BUCK-MORSS 1981, p. 169).

Além da matéria física, Adorno considera o material das ideias, teorias, conceitos, enfim, objetos do pensamento, como locus da verdade inintencional, pois esses tipos de materiais carregam consigo o atributo da transitoriedade: nascem, envelhecem e morrem. Todavia, se a verdade reside no objeto, é necessário que seu conteúdo seja liberado pelo sujeito racional, que se envolva numa experiência cognitiva. Para Adorno, esse sujeito deve imergir no objeto, aparelhado com uma certa arte de encontrar algo, uma ars inveniendi. Eis o papel da fantasia, de uma fantasia exata, que adira estritamente aos fatos, na ânsia da descoberta, do desvelamento da verdade objetiva (BUCK-MORSS 1981, p. 185).

Buck-Morss explica que a fantasia exata é científica, 
com o fito de não abandonar o objeto; mas também é artística, na medida em que reacomoda os seus elementos, abrindo-os à compreensão cognitiva. Desse modo, a lógica interna do objeto pode ser traduzida verbalmente, provocando a redefinição da linguagem como expressão da lógica da matéria.

Assim, a filosofia cumpre seu papel de apresentação da verdade. Ao invés de apropriar-se do objeto como se ele fosse uma mercadoria a ser transportada pela linguagem filosófica rumo ao mercado da intersubjetividade homogeneizadora, o objeto é que se converte, se traduz, se mimetiza em filosofia. Portanto, o objeto não se transporta, mas se transforma em palavras, e estas, em movimento contrário, transformam-se em imagens. A indiferença cede lugar à diferença; o pedantismo idealista cai por terra.

La transformación mimética puede ser vista como la reversión de la subjetividad kantiana. La creatividad de esta [...] residía en la capacidad del sujeto de proyectar en la experiencia sus propias formas y categorías a priori, absorbiendo dentro de sí el objeto. Pero el sujeto de Adorno deja la iniciativa al objeto; forma al objeto sólo en el sentido de transformarlo en una nueva modalidad. [...] La verdad como representación lingüística mimética suponía llamar a las cosas por sus nombres correctos (BUCK-MORSS 1981, p. 189).

Mas como expor a lógica interna dos objetos sem recorrer à ficção? Como a fantasia pode ser exata?

Segundo Buck-Morss, Adorno, em sua conferência de 1931, Die Aktualität der Philosophie, define a tarefa da filosofia como a construção de constelações. Adorno inspirara-se no estudo de Benjamin sobre a tragédia barroca alemã, Ursprung des deutschen Trauerspiels, no qual as constelações são a imagem central de sua teoria do conhecimento, esboçada no capítulo inicial do referido estudo (BENJAMIN 1985b).

No ensaio Ursprung des deutschen Trauerspiels, Benjamin 
pensa a experiência filosófica da verdade tomando por base os elementos das teorias do conhecimento de Platão e Kant, designando o conceito kantiano de experiência como conhecimento (Erkenntnis), adequado à ciência, distinto do conceito de experiência (Erfahrung) filosófica, adequada à revelação da verdade.

Se, em Kant, o sujeito constitui o mundo conforme suas próprias estruturas conceituais, em Benjamin são os fenômenos particulares, por intermédio das afinidades eletivas de seus elementos, que determinam, objetivamente, as ideias do sujeito. Enquanto o conhecimento kantiano é possessão, ao submeter a realidade às categorias do entendimento, a experiência filosófica benjaminiana é a representação das ideias com base naquela realidade.

Conceitualizar, para Benjamin, significa configurar os elementos do fenômeno, de modo que suas relações tornem-se visiveis para o intelecto, constituindo ideias que possam ser percebidas. Se, em Kant, o particular desaparece no "buraco negro" da abstração, em Benjamin, ele reemerge na ideia, na qual se transforma, por meio da configuração de seus elementos, como se, por assim dizer ao modo de Benjamin, as ideias fossem constelações e os fenômenos estrelas (BUCK-MORSS 1981, p. 197).

Benjamin faz convergir Platão e Kant quando admite que ideias são mais do que fenômenos, embora derivadas destes. Se, em Platão, as ideias aparecem como verdade do fenômeno, em Benjamin, o fenômeno é que aparece como verdade das ideias, mantendo a dignidade dos particulares. Desse modo, Benjamin propõe a redenção do mundo fenomênico, por meio da disposição de seus elementos em constelações eternas.

No final da década de 20, Adorno e Benjamin trabalha- 
ram juntos, com o intuito de desenvolver a teoria das constelações, valendo-se do referencial marxista. Por isso, em sua conferência inaugural de 1931, Adorno refere-se ao método de construção das constelações como programa de todo o conhecimento que se pretenda materialista e defende sua utilização não só para tratar do reino fenomênico, mas da própria história da filosofia.

De fato, Adorno busca a liquidação da tradição por intermédio da crítica imanente de seus conceitos; por essa razão, elogia o Trauerspiel, considerando sua importância na redenção do raciocínio indutivo. Ao invés de subsumir o particular no geral, a teoria de Benjamin mantém a autossuficiência da ideia como constelação dos elementos do particular. Cada ideia mostra-se, pois, como uma mônada que contém em si a totalidade, ou seja, uma "imagem do mundo”. No entanto, essas constelações do mundo fenomênico são descontínuas, uma vez que cada ideia é diferente de outra ideia, não havendo, por conseguinte, hierarquias, dependência ou paridade entre elas, como se cada uma delas fosse um sol, iluminando a verdade com luz própria.

Ao expor essa teoria sobre bases materialistas, Adorno pretende transformar a filosofia num poderoso método de interpretação, numa lógica da desintegração. Agora, a ideia, a mônada, é o conteúdo social em sua especificidade e esse conteúdo social é o conteúdo de verdade a ser buscado na diferença. Acerca desse método, comenta o filósofo espanhol José Antonio Zamora: "Sólo abismándose sin reservas en las cosas, en su dimensión histórica, puede la crítica sacar a la luz lo que ha quedado pendiente y dar expresión al derecho de lo posible frente a lo que existe" (ZAMORA 1996, p. 72). Adorno, nesse sentido, redime a filosofia ao relativizar a décima primeira tese de Marx sobre Feuerbach: 
interpretar já é transformar o mundo.

Talvez por isso, a obra de arte (Kunstwerk), para Adorno, não se confunde simplesmente com algo fabricado, com o artefato (Artefact). A obra é coisa feita, elaborada, viva, que possui sua linguagem própria. No artefato, a gênese, ou o momento do fazer, não se distingue qualitativamente do produto social realizado, ficando inscrito nos limites da utilidade. Na obra de arte, esses dois momentos separam-se qualitativamente; em vez de cumprir o intencional destino utilitário, prometido pela gênese, como no artefato, a arte exprime, esteticamente, os problemas que a sociedade não foi capaz de resolver. Enquanto o artefato é um objeto (Ding), a obra de arte é uma coisa (Sache), ou seja, ela é ao mesmo tempo devir e resultado.

Nesse distanciamento da empiria, cada obra de arte aspira à unidade, à forma integral, mas não o consegue. A aparência formal é, inintencionalmente, condicionada pelos impulsos individuais que a constituem e ameaçam constantemente. É o que Adorno designa de astúcia da racionalidade estética.

Na obra de arte, o uno e o múltiplo se atraem e se repelem. Essa tensão entre forças centrípetas e centrífugas é que dá movimento à obra, caracterizando sua unidade como uma unidade viva, instável. A obra que apresenta uma forma plena e estabilizada é autoritária, porém, não intensa, por pretender reprimir os particulares. A esse entrelaçamento do uno com o múltiplo, Adorno designa de intensidade: "A intensidade é a mimese realizada pela unidade, cedida pela multiplicidade à totalidade [...]" (ADORNO 1982, p. 212). Esta é uma totalidade aberta, na medida em que ilumina os pormenores e é iluminada por eles.

Essa abertura ao fragmentário, ao inconciliável, mobili- 
zada pela dialética da forma, é que constituirá a profundidade da obra: "São profundas as obras de arte que não mascaram as divergências ou as contradições, nem as deixam inconciliadas. Ao forçá-las à aparição, que é tirada do inconciliado, as obras encarnam a possibilidade de uma conciliação" (ADORNO 1982, p. 215).

É graças à articulação desses elementos contraditórios que a obra de arte adquire a sua forma e, na mesma medida, a possibilidade de seu declínio. Isso porque a articulação é uma categoria ao mesmo tempo formal e material. A consequência desse estado de inconciliabilidade entre o idêntico e o não-idêntico é que, condicionado pela má infinitude, o não-poder-concluir deve tornar-se princípio de expressão e procedimento da arte contemporânea: "A unidade das obras de arte não pode ser o que ela deve ser, a unidade da variedade: ao sintetizar, ela viola o sintetizado e prejudica nele a síntese. As obras de arte sofrem tanto na sua totalidade mediatizada, como nas suas imediatidades" (ADORNO 1982, p. 169).

A expressão estética é, portanto, a objetivação do conteúdo social, sedimentado nos materiais por meio da mediação subjetiva do artista: "[...] é objectivação do inobjectivo de tal sorte que, pela sua objectivação, se torna num segundo inobjectivo, no que se exprime a partir do artefacto e não como imitação do sujeito" (ADORNO 1982, p. 131). No entanto, apesar dessa abertura, as obras de arte são mônadas fechadas umas para as outras, sem janelas. Melhor: cada obra é, ao mesmo tempo, coisa e centro de forças: "As obras de arte estão fechadas umas para as outras, são cegas e, apesar de tudo, representam no seu hermetismo o que se encontra no exterior" (ADORNO 1982, p. 204).

Todavia, esse hermetismo já contém o exterior, na me- 
dida em que é capaz de imobilizá-lo, transformando suas categorias em linguagem universal. Nas obras de arte, interagem, inconscientemente, o universal e o particular. Daí advém que o papel de uma estética dialética seja o de elevar tal interação à consciência, por intermédio da análise imanente das obras.

Outrossim, não se deve descuidar do caráter ambíguo da arte. Ao mesmo tempo que reflete a sociedade, ela é um como se; se é um produto do trabalho social do espírito, é também denúncia da sociedade de troca total, onde tudo existe para-outra-coisa. Seu aspecto associal é a negação determinada de uma determinada sociedade, o que a torna social enquanto movimento imanente contra a sociedade. Sua função social é sua ausência de função; seu encantamento é desencantamento, um ser-para-si que se relaciona com o outro. Autônoma e heterônoma, a obra de arte é um interior que já contém o exterior, uma mônada sem janelas que aglutina em si o universal e o contingente; sua verdade é sua aparência total. A arte - enquanto produto dessa tensão e recusando a síntese idealista -, para não se tornar mercadoria, reifica-se; para não comunicar, torna-se enigmática, resistindo a todo custo à integração no mundo administrado. Para Adorno, a "arte representa o que não se deixa organizar e o que oprime a organização total" (ADORNO 1982, p. 263).

Para que apreendamos essa relação da forma artística com a sociedade, é necessário que analisemos menos o momento de sua recepção do que o momento de sua produção. Com efeito, Adorno rechaça a falsa intersubjetividade como parâmetro de julgamento das obras. Ao integrarse no circuito da comunicação, a arte é neutralizada. A comunicação no mundo vigente é a comunicação da falsa 
consciência, da consciência reificada.

Assim, Adorno desconfia da promessa de um juízo estético que se legitime mediante seu alargamento no circuito social. A aposta no momento da circulação, como suporte único para a análise estética, ou mesmo como paradigma para a análise sociológica em geral, parece desconsiderar a possibilidade de ruptura, apontando muito mais para a reconciliação, para a realização de um contrato intersubjetivo, escorado no modelo do juízo de gosto. Menos otimista, Adorno prefere manter a imagem da catástrofe como promessa da arte; não há contrato possível sem a ruptura objetiva com a falsa totalidade, sem a superação do ente.

Esse Kulturpessimismus (ROUANET 1985, p. 314) de Adorno deve ser interpretado menos como princípio filosófico do que como constatação do estado de coisas administrado pela indústria da cultura. Analisar o potencial da arte pelo prisma de sua circulação, por intermédio da rede dos mass media, é não compreendê-la como um fenômeno contraditório que tem algo mais a dizer do que o que se quer que ela diga. Ora, é no momento da produção que ocorre o processo de sedimentação dos antagonismos sociais nas obras, momento constitutivo de seus centros de força. É na produção que se condensa a tensão entre o caráter mimético e o construtivo, a articulação entre o real e o utópico, que confere o caráter enigmático às obras.

Em suma, para Adorno, a hermenêutica não salva; sua função é resolver objetivamente o enigma de cada obra, obtendo seu conteúdo social de verdade: "as obras de arte são enigmáticas enquanto fisionomia de um espírito objetivo [...]" (ADORNO 1982, p. 149). Esse enigma, compreendido dialeticamente, é zona de indeterminação entre o inacessível e o realizável. 
Mas, porque a utopia, o não-ente, se encontra para a arte velada de negro, permanece, em todas as suas mediações, como lembrança, a lembrança do possível contra o real que a reprime, algo como a compensação imaginária da catástrofe da história do mundo, liberdade que, sob a influência da necessidade, não existiu e acerca da qual não se sabe se pode existir. Na sua tensão para a catástrofe permanente, a negatividade da arte está ligada à méthexis [participação] na obscuridade (ADORNO 1982, p. 156-157).

Tal linguagem enigmática convida o intérprete das obras a mergulhar na imanência, para além da carga de sentidos impressa nos materiais pelo mundo administrado. $\mathrm{Ou}$ seja, o trabalho de interpretação pode encontrar a transcendência a partir da própria finitude. Isso é possível, na medida em que a forma artística é resultado da conjunção de dois fenômenos presentes no momento da produção das obras: mímese e construção. $O$ que Adorno denomina de mímese na arte é o pré-espiritual, aquilo que provém da empiria, da natureza, da realidade exterior; é o que se opõe ao espírito. Por construção, designa o elemento espiritual, a forma das obras, a objetivação dos impulsos miméticos ou, se quisermos, o representante da lógica e da causalidade no âmbito da arte; ou ainda, a racionalidade das obras. Desse modo, a construção reunifica os elementos do real no contexto da obra, libertando-os da contingência, transformando sua qualidade e inserindo-os no universal. A construção anuncia o novo, almeja tornar-se um real sui generis, um ser à segunda potência, continuando, no entanto, prisioneira da aparência. Essa tensão entre o mimético e o construtivo reproduz, na forma das obras, a tragédia social. A tensão é a demarcação de um limite, não de uma impossibilidade:

Pois a arte e as suas obras são apenas o que se podem tornar. Porque nenhuma obra consegue resolver totalmente a sua tensão imanente; porque a história ataca, finalmente, a ideia de uma tal resolução, a 
teoria estética não pode contentar-se com a interpretação das obras de arte existentes e do seu conceito. Ao virar-se para o seu conteúdo de verdade, é impelida, enquanto filosofia, para lá das obras (grifo nosso, ADORNO 1982, p. 394).

\section{CONCLUSÃO}

Salta à evidência a ubiquidade da estética de Adorno. Restringir sua jurisdição ao âmbito estrito da análise das obras de arte está muito aquém de sua potencialidade. Assim como a terceira crítica de Kant, e para muito além dela, a Teoria Estética de Adorno renova a pergunta pelo que não foi alçado pela lógica formal à condição de conceito, afastando a filosofia da inteligibilidade dos fenômenos. Ou seja: como o fez Kant, Adorno convida a razão e o entendimento a libertar-se de seus imperativos, a arejar-se por meio da aproximação dialética com a sensibilidade. Melhor: Adorno se interroga pela condição de possibilidade de um pensamento crítico capaz de compreender o mundo como ele é, sem esquecer do que ele não pôde ter sido, e empenhado, de modo responsável, no que ele deve ser, para que o resgate do futuro seja possível a partir da atualidade do existente. Nesse sentido, além de redimir a própria metafísica, o conteúdo de verdade dos campos de força da teoria estética dialética de Adorno pode atrair a intelligentsia filosófica para que renove sua capacidade de expressão dos problemas do mundo contemporâneo.

Abstract: Adorno's aesthetic is organized in fields of force, under which orbiting constellations of categories which reflect the truth of the managed world in the era of late capitalism. Understand the nuances of this aesthetic is preparing to reinterpret the world, so as to achieve the things forgotten by the concept. In this sense, the aesthetic becomes a way of reconnecting the human sciences with the reality, from the recovery of sensitivity troubled by the dominance of instrumental reason. 
Keywords: Adorno; Aesthetics; Human Sciences.

\section{REFERÊNCIAS}

ADORNO, Theodor Wiesengrund. Teoria estética. Lisboa: Edições 70, 1982.

. Dialectica negativa. Madrid: Taurus, 1975.

BENJAMIN, Walter. Teses sobre filosofia da história. São Paulo: Ática, 1985a.

. Origine du drame barroque allemand. Paris: Flammarion, $1985 b$.

BUCK-MORSS, Susan. Origen de la dialectica negativa. Mexico: Siglo Veintuno, 1981.

JAY, Martin. As ideias de Adorno. São Paulo: Cultrix, 1988. JIMENEZ, Marc. Para ler Adorno. Rio de Janeiro: Francisco Alves, 1977.

RILKE, Rainer Maria. Rodin. Rio de Janeiro: RelumeDumará, 1995.

ROUANET, Sérgio Paulo. A razão cativa: as ilusões da consciência, de Platão a Freud. São Paulo: Brasiliense, 1985.

SCHOENBERG, Arnold. Fundamentos da composição musical. São Paulo: Edusp, 1991.

WISNIK, José Miguel. O som e o sentido: uma outra história das músicas. São Paulo: Companhia das Letras; Círculo do Livro, 1989.

ZAMORA, José Antonio. Religion tras su final: Adorno ver- 
sus Habermas. Bragança Paulista: Edusf, 1996. 